\title{
ON A SYSTEM OF REGULARIZED NONCONVEX VARIATIONAL INEQUALITIES
}

\author{
QAMrUl HaSAN AnsARI AND JAVAD BALOOEE
}

Abstract. In the present paper, we point out that the basic result, which is the main tool, in [D. J. Wen, Projection methods for a generalized system of nonconvex variational inequalities with different nonlinear operators, Nonlinear Anal. 73 (2010) 2292-2297] has some fatal errors. Therefore, the results and algorithms in the above mentioned paper are no longer valid. To overcome with the problems in the above mentioned paper, we introduce a system of regularized nonconvex variational inequalities (SRNVI) and establish an equivalence between this system and a fixed point problem. By using this equivalence, we suggest a projection iterative algorithm for solving SRNVI. Furthermore, we also prove the existence and uniqueness of a solution of SRNVI. The convergence analysis of the suggested iterative algorithm is studied. As a consequence, we derive the correct version of the algorithms and results presented in the above mentioned paper.

Mathematics subject classification (2010): 49J40.

Keywords and phrases: System of regularized nonconvex variational inequalities, uniformly $r$-proxregular sets, iterative schemes, convergence analysis.

\section{REFERENCES}

[1] J. F. NASH, Non-cooperative games, Ann. Math. 54 (1951), 286-295.

[2] J. F. NASH, Two-persons cooperative games, Econometrica 21 (1953), 128-140.

[3] Q. H. ANSARI AND J. C. YAO, A fixed point theorem and its applications to the system of variational inequalities, Bull. Austral. Math. Soc. 59 (1999), 433-442.

[4] Q. H. ANSARI AND J. C. YAO, System of generalized variational inequalities and their applications, Appl. Anal. 76 (3-4) (2000), 203-217.

[5] J. P. Aubin, Mathematical Methods of Game Theory and Economic, North-Holland, Amsterdam (1982).

[6] C. Cohen And F. Chaplais, Nested monotony for variational inequalities over product of spaces and convergence of iterative algorithms, J. Optim. Theory Appl. 59 (1988), 360-390.

[7] J. S. PANG, Asymmetric variational inequality problems over product sets: Applications and iterative methods, Math. Prog. 31 (1985), 206-219.

[8] S. S. Chang, H. W. Joseph Lee, C. K. Chan, Generalized system for relaxed cocoercive variational inequalities in Hilbert spaces, Appl. Math. Lett. 20 (2007), 329-334.

[9] Z. HuAng, M. A. NOoR, An explicit projection method for a system of nonlinear variational inequalities with different $(\gamma, r)$-cocoersive mappings, Appl. Math. Comput. 190 (2007), 356-361.

[10] R. U. Verma, Generalized system for relaxed cocoercive variational inequalities and projection methods, J. Optim. Theory Appl. 121 (2004), 203-210.

[11] R. U. Verma, General convergence analysis for two-step projection methods and applications to variational problems, Appl. Math. Lett. 18 (2005), 1286-1292.

[12] R. U. Verma, Projection methods, algorithms, and a new system of nonlinear variational inequalities, Comput. Math. Appl. 41 (2001), 1025-1031.

[13] D. J. WEN, Projection methods for a generalized system of nonconvex variational inequalities with different nonlinear operators, Non. Anal. 73 (2010), 2292-2297. 
[14] M. BOUNKHEL, L. TADJI, A. HAMDI, Iterative schemes to solve nonconvex variational problems, J. Inequal. Pure Appl. Math. 4 (2003), 1-14.

[15] F. H. Clarke, Y. S. Ledyaev, R. J. Stern, P. R. Wolenski, Nonsmooth Analysis and Control Theory, Springer-Verlag, New York (1998).

[16] F. H. Clarke, R. J. Stern, P. R. Wolenski, Proximal smoothness and the lower $C^{2}$ property, J. Convex Anal. 2 (1995), 117-144.

[17] L. P. PANG, J. Shen, H. S. Song, A modified predictor-corrector algorithm for solving nonconvex generalized variational inequalities, Comput. Math. Appl. 54 (2007), 319-325.

[18] R. A. Poliquin, R. T. Rockafellar, L. Thibault, Local differentiability of distance functions, Trans. Amer. Math. Soc. 352 (2000), 5231-5249.

[19] F. H. Clarke, Optimization and Nonsmooth Analysis, Wiley-Interscience, New York (1983).

[20] M. BounKhel, Existence results of nonconvex differential inclusions, Port. Math. (N.S.) 59 (2002), 283-309.

[21] M. BounKheL, General existence results for second order nonconvex sweeping process with unbounded perturbations, Port. Math. (N.S.) 60 (2003), 269-304.

[22] M. BounKhel, L. AZZAM, Existence results on the second order nonconvex sweeping processes with perturbations, Set-valued Anal. 12 (2004), 291-318.

[23] A. Canino, On p-convex sets and geodesics, J. Diff. Equation 75 (1988), 118-157. 